\title{
To What Extent Do Parents of Montessori-Educated Children "Do Montessori" at Home? Preliminary Findings and Future Directions
}

\author{
Jill K. Walls \\ Ball State University \\ Acknowledgments \\ Support for this project was provided by a research mini-grant from the American Montessori Society \\ (AMS).
}

Keywords: Montessori parenting, parenting practices, early childhood, home-school connections

\begin{abstract}
Few if any empirical studies have explicitly examined the home environments of Montessori-educated children or, more specifically, the question of whether Montessori parents reinforce or undermine their child's Montessori education at home. With a convenience sample of 30 parents of toddlers and preschoolers attending a private Montessori school in the Midwest, this cross-sectional study examines parents' knowledge of Montessori principles and their parenting beliefs and behaviors at home. Results suggest that Montessori parents from the target school were knowledgeable about and valued Montessori principles, even though few had had a Montessori education themselves. Parents in this sample varied in their parenting behaviors and choices at home, with some parents who intentionally reinforced Montessori principles and others whose behaviors were inconsistent with a Montessori approach. Findings from this preliminary study provide a first glimpse into the beliefs and behaviors of Montessori parents upon which future studies can build. Montessori educators and administrators will benefit from future research involving Montessori parents, particularly those schools that offer Montessori-based parenteducation sessions to the families they serve.
\end{abstract}

Although a number of studies have demonstrated the benefits of a Montessori education for young children, few if any have explicitly examined the home environments of Montessori-educated children. Prior research, including one recent longitudinal study of preschoolers, suggested that Montessori children tend to score higher on academic and behavioral skills compared to their non-Montessori peers (Lillard, 2012; Lillard \& Else-Quest, 2006; Lillard et al., 2017). It is largely assumed that parents select a Montessori education for their child because it aligns with their educational values and goals for the child, but some authors have suggested that Montessori-educated children do not necessarily receive Montessori-based parenting at home (McFarland \& McFarland, 2013). Also, Montessori principles are generally 
misunderstood by the public and perhaps even by parents who select Montessori education for their child (Murray, 2012). The degree to which parents who select Montessori education for their child intentionally "do Montessori" at home has not been examined empirically. This gap in the literature is notable because children's educational outcomes are jointly shaped by home and school contexts (Bronfenbrenner \& Morris, 1998). Understanding Montessori children's home environments can allow researchers and educators to identify key family and home factors that promote or hinder academic success within a Montessori setting. In the present study, doing Montessori at home is conceptualized as providing a physical environment that children can easily navigate and that offers opportunities for children to care for themselves and their environments (Woo, 2014). Doing Montessori at home is assessed according to the types of materials children have access to, how their materials are stored, their level of involvement in practical life activities, and parents' beliefs and behaviors in relation to their child's activities at home.

In a recent longitudinal study employing a nationally representative sample of young children in traditional public education settings, El Nokali, Bachman, and Votruba-Drzal (2010) examined the relationships between parental involvement and children's social and academic outcomes. They concluded that "further exploration of how parents and teachers may be jointly responding to children's social and behavioral skills could help to elucidate the potential benefits of parent involvement...” (El Nokali et al., 2010, p. 1003). Because so little is known about the home lives of Montessori-educated children, the current study provides a first glimpse into an understudied population of parents by examining the beliefs and behaviors of parents of Montessori-educated toddlers and preschoolers at a private Montessori school in the Midwest. This study's results can inform future research questions that use larger and more diverse samples of Montessori parents. Findings from this study and others like it may also reveal opportunities for Montessori educators to foster home-school relationships and enhance children's educational experiences at home.

\section{Theoretical and Empirical Background}

Ecological theory posits that children's development is shaped by their interactions and experiences within multiple interrelated contexts (Bronfenbrenner \& Morris, 1998). Inspired by ecological theory, the overlapping spheres of influence model similarly emphasizes how aspects of home and school environments overlap in meaningful ways to produce different outcomes among children (Epstein, 2001). Establishing home-school partnerships is a priority for Montessori and non-Montessori schools alike. Stronger home-school partnerships and greater parental involvement in children's education are thought to positively affect children's learning and development (Bronfenbrenner \& Ceci, 1994; Epstein, 2001; Galindo \& Sheldon, 2012; Knoche \& Witte, 2016). However, the benefits of parental involvement in children's schooling may depend in part on whether parents' involvement reinforces, or undermines, school curricula and culture. For some children, home and school are very different worlds that have different sets of expectations and resources. The extent to which children reap the benefits of a Montessori education is likely influenced by the degree of fit between Montessori principles and the parenting they receive at home (Ansari \& Winsler, 2014; Havis, 2009).

The term home-school dissonance has been used to describe discrepancies between home and school in beliefs, values, and expectations (Phelan, Davidson, \& Cao, 1991). Phelan et al. (1991) theorized that significant home-school dissonance, which is caused by the stress children experience when navigating inconsistencies between home and school, harms their development. Montessori-educated children whose home environments undermine or contradict Montessori principles-through differences in the physical setting, adults' expectations of them, or the nature of their interactions with adults-may experience greater cognitive dissonance and stress than children whose home environments are more similar to their school culture (Phelan et al., 1991). The absence of formal testing of those associations further underscores the importance of understanding variability in the parenting beliefs and behaviors of Montessori parents.

Montessori children may experience inconsistencies between their home and school environments in several ways, from the manner in which their materials are stored to the nature of their interactions with adults in both settings (McCarthey, 2000). Foundational to Montessori education is the assumption that 
children are self-motivated learners who will thrive in an environment that offers them freedom of choice within a structured, developmentally appropriate setting. Similar to a Montessori classroom, Montessoriinspired homes may include prepared environments that provide children with access to developmentally appropriate materials on open shelving and at their eye level, for example. Adults in Montessori classrooms foster children's development by serving as gentle guides and role models, using careful observation and limited direction. Maria Montessori wrote, "When we give the child freedom and independence, we are giving freedom to the worker already braced for action, who cannot live without working and being active" (Montessori, 1995, p. 91). Applied to the home setting, parents who direct children's day-to-day activities, or who micromanage their actions, hinder children's natural desire for self-mastery.

Parenting styles (i.e., general attitudes toward parenting that differ based on levels of warmth and behavioral control) have long predicted a variety of child outcomes (Baumrind, 1967). Authoritative parents provide their child with affection and guidance to promote children's autonomy in a supportive and typically nonpunitive environment. Authoritarian parents value obedience and conformity and tend to be demanding, rigid, and restrictive. Permissive parents, while warm and loving, do not enforce rules or behavioral standards for children and are described in the parenting literature as lax or spoiling (Baumrind, 1991). Generally speaking, authoritative parenting and the democratic beliefs that underlie this approach to childrearing yield positive developmental outcomes among children (Darling \& Steinberg, 1993; Steinberg, Lamborn, Dornbusch, \& Darling, 1992; Schofield \& Weaver, 2016). Authoritative parenting is aligned with a Montessori education, balancing children's needs for nurturance and guidance with opportunities for selfdirection (American Montessori Society, n.d.). As such, it is plausible that authoritarian and permissive styles undermine a Montessori education.

Dr. Montessori made specific recommendations for the role of adults in children's lives: they should respect children and honor their innate drive toward exploration and self-mastery (e.g., Montessori, 1970). Accordingly, the instructions for teachers and for parents were very similar. Although Montessori teachers receive specialized training to effectively implement Montessori principles, the same is not true of parents. Thus, although Montessori schools generally work from a similar educational framework, we may expect greater variability in children's home experiences. Schools may foster home-school relationships by encouraging parents' involvement in school events or by offering opportunities for parents to better understand Montessori principles via parent-education workshops. The content, format, duration, and quality of these sessions vary, and no established standards or guidelines for Montessori-based parent education currently exist. As a precursor to developing meaningful and relevant parent-education workshops, Montessori teachers and administrators may benefit from understanding parents' beliefs, behaviors, and educational goals for their child. Because of socioeconomic, cultural, or other factors, Montessori parents likely vary in their beliefs about child development and parenting goals, which may be an important difference between home and school settings (McCarthey, 2000). Parent-education programs that successfully create positive connections between school and home may enhance the benefits children receive from a Montessori education.

\section{The Current Study}

Consistent with ecological theory and the concept of home-school dissonance, it is theorized that children may benefit from receiving parallel messages at school and home about their capabilities, the expectations for their behavior, and the manner in which adults interact with them (Phelan et al., 1991). Few if any studies have examined the home lives of Montessori-educated children, leaving a gap in our understanding of parenting variations within this population. In the current study, doing Montessori at home is conceptualized in terms of the physical environment at home, the degree to which children have freedom within that environment, and how parents interact with their child. Specifically, authoritative parenting, a value for children's autonomous work, and nonpunitive discipline strategies are consistent with Montessori principles. In response to the notable lack of information on Montessori parents, the following exploratory research questions were investigated: 
- Do parents of Montessori-educated children understand basic Montessori principles?

- To what degree are parents intentional about doing Montessori at home?

- What are the parenting beliefs, styles, and discipline strategies of parents who select a Montessori education for their child?

- Is knowledge of Montessori principles associated with parenting beliefs and behaviors?

- Are parents' discipline strategies associated with other parenting behaviors and specifically those thought to reflect doing Montessori at home?

\section{Method}

\section{Participant Recruitment}

The target group for this study was parents of children ages 18 months to 6 years attending a private Montessori school in the Midwest. Families with at least one child in the Toddler or Primary room were recruited through flyers, emails, and word of mouth. The author also announced the study at a parenteducation event hosted by the school. Of the 48 eligible families, 30 consented to participate in the study. Participating families received a \$10 incentive and one hour of credit toward their volunteer obligations at the school. This study received approval to conduct research with human subjects from the institutional review board of the author's research institution.

\section{Sample}

The final sample consisted of 30 participants (25 biological mothers and five biological fathers). Parents' ages ranged from 22 to 49 years $(M=35.47, S D=6.10)$. Eighty-four percent of parents selfidentified as White, $13 \%$ as Asian, and $3 \%$ as other. The vast majority of the sample (90\%) was married and college educated, with $76 \%$ holding at least a 4-year degree. Average family household income was approximately $\$ 226,000$ per year (range $=\$ 35,000-\$ 900,000, S D=\$ 188,000)$. Nineteen $(63 \%)$ of the children of participating parents were enrolled full-time, and 11 (37\%) were enrolled part-time (i.e., half day). At the time of the survey, children had been attending the target school, on average, slightly longer than one year ( $M=14.60$ months, $S D=11.14$ months). Parents' choice of school was driven by two main factors: a value of Montessori education and the specializations of the teachers and learning environment, and convenience or location. Cost, hours of operation, and reputation of the school ranked lower in influence on parents' school selection (Table 1).

\section{Data Collection}

One parent from each family completed an anonymous online survey, prepared using Qualtrics software (Qualtrics, 2018), which included both fixed-response and open-ended questions. In addition to standard demographic information (e.g., race, marital status, income), parents responded to questions about their reasons for selecting a Montessori school, their general understanding and endorsement of Montessori principles, the manner in which children's materials were stored in their home, opportunities for children's autonomy at home, discipline strategies, and parenting style and beliefs about child development. To gather more detailed information, open-ended questions followed some of the fixed-response questions, allowing parents to elaborate on their responses. All participants completed $100 \%$ of the survey, and there were very few missing data on individual items. 
Table 1

Parents’ Top-Ranked Reasons for Selecting the Target Montessori School

\begin{tabular}{lcc}
\hline \multicolumn{1}{c}{ Reason } & $n^{*}$ & $\%$ \\
\hline Montessori philosophy & 24 & 80 \\
Location & 16 & 53 \\
Qualifications of teachers/staff & 14 & 47 \\
Classroom environment & 10 & 33 \\
Teacher-child ratio & 8 & 27 \\
Cost & 6 & 20 \\
Reputation of the school & 5 & 17 \\
Recommendation from someone & 5 & 17 \\
Hours of operation & 4 & 13 \\
Other & 1 & 3
\end{tabular}

${ }^{*}$ Number of parents who ranked that option as one of their top three reasons for choosing the target Montessori school.

\section{Measures}

Demographic variables. All parents, when offered a choice of four genders (i.e., male, female, transgender, nonbinary), self-identified as either male or female. Ethnicity categories included Black, Asian, American Indian or Alaska Native, Native Hawaiian or Pacific Islander, White, or other. Parents also reported their age, highest level of education completed, annual household income, marital status, and relationship to the target child. (Biological parents comprised $100 \%$ of the sample.)

Montessori knowledge. Parents' understanding of Montessori principles was assessed with several fixed-response questions. It was not the intent to test parents on Montessori principles or their knowledge of specific activities or works, but rather to get a general sense of how their perspectives aligned with a Montessori approach. Parents indicated the degree to which they (a) were comfortable educating friends and colleagues about Montessori principles, (b) were knowledgeable about the target school's behavioral and academic expectations for their child, (c) attended parent-education events at the target school, (d) researched information about Montessori principles, (e) experienced Montessori education as a child, and (f) had formal training in Montessori principles. Responses ranged from 1 (disagree) to 4 (agree), with higher scores indicating greater Montessori knowledge.

Montessori application at home. The degree to which parents do Montessori at home was measured directly by asking parents to indicate the degree to which they agreed with the statements "I run my home in a way that is consistent with Montessori principles" and "My child has similar expectations at school and at home," on a scale from 1 (disagree) to 4 (agree). Parents also were asked to explain, in their own words, the location and manner in which their child's materials were stored at home, as well as how decisions about storing those materials were made. Parenting behaviors and styles were also considered as evidence of doing Montessori at home.

Parenting beliefs and behaviors. Parents' beliefs about young children's development were measured with four items: "Children learn best from hands-on activities," "Children should respect adults," "Younger children can learn a good deal by interacting with older children," and "It is possible for young children to engage in uninterrupted work for 2-3 hours at a time." (Children of parents who participated in this study regularly engaged in 2- to 3-hour work cycles at school.) Parents responded to 11 items that reflected the degree to which they promoted their child's autonomy and self-directed play at home and their patience with and respect for their child. Response options to the parenting beliefs and behaviors questions ranged from 1 (disagree) to 4 (agree). Agreement with items such as "I encourage my child to take 
responsibility for his/her belongings" and "I encourage my child to do things for himself/herself, such as putting on shoes" reflected doing Montessori at home because those parental behaviors encourage children's independence and self-mastery, a recognized feature of the Montessori Method. Due to the exploratory and descriptive nature of this study, questions that reflected doing Montessori at home were analyzed separately and were not combined to form a scale.

Parenting style. Using a scale ranging from 1 (never) to 6 (always), parents indicated how often they engaged in parenting practices that were later grouped into subscales for authoritative, authoritarian, and permissive parenting styles (Robinson, Mandleco, Olsen, \& Hart, 1995). Sample items included "I am responsive to my child's feelings and needs" (i.e., authoritative), "I use threats as a form of punishment with little or no justification" (i.e., authoritarian), and "I give into my child when he/she causes a commotion about something” (i.e., permissive). Mean scores were computed for each parenting style.

Discipline strategies. Given a list of discipline strategies supplied by the researcher, parents were first asked to indicate whether they had ever used the strategies with their child. The list included a variety of strategies for active discipline (e.g., time-out, open discussions), passive discipline (e.g., ignoring the behavior), and harsh discipline (e.g., spanking, threatening). Parents received one point for each strategy they reported having used. Points were added together to form subscale scores for active, passive, and harsh discipline, with higher scores indicating greater use of each type of discipline strategy. Parents also explained in their own words which strategies they used most often and why. Active and positive discipline strategies were considered to be consistent with Montessori principles; harsh and passive discipline strategies were considered to be inconsistent with Montessori principles (Pottish-Lewis, 2011).

\section{Results}

\section{Parents’ Knowledge of Montessori}

Descriptive statistics were analyzed for several questions thought to reflect parents' general understanding of Montessori principles. On a scale from 1 (disagree) to 4 (agree), most parents said they felt comfortable describing Montessori philosophy to a friend or colleague $(M=3.50, S D=0.68)$, viewed Montessori education as different from traditional public education $(M=3.83, S D=0.46)$, and preferred Montessori education to traditional public education $(M=3.57, S D=0.73)$. Similarly, parents highly rated their knowledge of their school's academic and behavioral expectations of their child highly $(M=3.57, S D$ $=0.63 ; M=3.90, S D=0.31$, for academic and behavioral expectations, respectively). Very few respondents (or their partners, when applicable) had first-hand experience with Montessori education as a child ( $n=1$, $3 \%)$ or formal training in Montessori principles $(n=1,3 \%)$.

\section{Are Montessori Parents Doing Montessori at Home?}

Descriptive statistics were analyzed for questions designed to reflect explicit and implicit application of Montessori principles at home. On average, parents indicated they ran their home "in a way that is consistent with Montessori principles" $(M=2.83, S D=0.69)$ and that their child had similar behavioral expectations at home and school $(M=3.23, S D=0.73)$. Parents generally agreed with the statement "I intentionally store my child's belongings in a location where he/she can reach them" $(M=$ 3.37, $S D=0.72$ ). Open-ended questions allowed parents to describe how and where children's materials were stored. All parents indicated one or more of the following storage or display methods: open shelving, bins or tubs (open or clear plastic), or baskets. Half of the sample reported storing or displaying children's materials in a designated space such as a playroom or toy room, and others reported storing items in the bedroom (33.3\%), living room (26.6\%), or basement (10\%). Half of parents (50\%) said they intentionally stored or displayed their child's materials in this way, based on their understanding of Montessori principles, because they perceived it to be age appropriate or because they wanted items to be accessible. Some parents organized their child's materials because of physical space limitations (26.6\%) or for convenience or easy 
cleanup (26.6\%). Only two parents said their method of storing or displaying children's materials was arbitrary. As one parent wrote, "It just happened."

A second set of questions reflected parenting behaviors related to children's development of autonomy, an important developmental goal of Montessori education (see Table 2). Pearson correlations (see Table 3) suggest that parents who scored themselves higher on patience were more likely to say they respected their child $(r=.53, p=.00)$; offered their child choices $(r=.45, p=.01)$; encouraged their child to do things for themselves, such as putting on shoes $(r=.36, p=.05)$; and encouraged their child to choose their own clothing $(r=.43, p=.02)$. Although too few fathers responded to make a statistically meaningful comparison to mothers, fathers' average scores for "I offer my child choices" were somewhat higher than for mothers $(M=4.00, S D=0.00$ for fathers; $M=3.40, S D=0.50$ for mothers $)$.

Table 2

Descriptive Statistics for Parenting Variables That Reflect Doing Montessori at Home

\begin{tabular}{lccc}
\hline \multicolumn{1}{c}{ Statement } & Range & $M^{*}$ & $S D$ \\
\hline I offer my child choices. & $1-4$ & 3.50 & 0.51 \\
My child chooses what he/she wears. & $1-4$ & 3.17 & 0.65 \\
I encourage my child to do things for him/herself. & $1-4$ & 3.73 & 0.45 \\
My child is free to choose his/her own activities at home. & $1-4$ & 3.40 & 0.56 \\
I give my child opportunities to be independent at home. & $1-4$ & 3.50 & 0.51 \\
I respect my child. & $1-4$ & 3.57 & 0.50 \\
I encourage my child to take responsibility for his/her belongings. & $1-5$ & 4.23 & 0.68 \\
\hline
\end{tabular}

"Higher means indicate greater agreement with the statements.

Parents also reported how often their child participated in food preparation at home, an activity that is encouraged within a Montessori school environment. One parent reported their child never participated in food preparation at home. Other parents' responses were as follows: six parents (20\%) selected "rarely" (i.e., less than once per week), 18 parents (60\%) selected "sometimes" (i.e., 1-3 times per week), and five parents (17\%) selected “often” (i.e., 4 or more times per week).

\section{Montessori Parents’ Beliefs, Parenting Styles, and Discipline Strategies}

Consistent with the Montessori approach of multiage classrooms, most parents agreed with the statement "Younger children can learn a good deal by interacting with older children" $(M=3.63, S D=$ 0.49). Parents also agreed, albeit to a lesser degree, with the statement "It is possible for young children to engage in uninterrupted work for $2-3$ hours at a time" $(M=2.87, S D=0.82)$. A one-way repeated measures analysis of variance was conducted to compare parents' scores on the three parenting-style variables. Results suggest significant mean differences in parenting styles $(F(2,28)=176.55, p=.00)$. Pairwise comparisons suggest that parents scored significantly higher on authoritative parenting $(M=4.97, S D=$ $0.49)$ than on permissive parenting $(M=2.47, S D=0.73)$ or authoritarian parenting $(M=2.06, S D=0.64)$.

When respondents were asked about discipline strategies used at home, 52\% indicated they used open discussions, reasoning, or problem-solving with their child because "children understand" or are "very smart," and many perceived that open discussions yielded more positive responses. Fewer parents reported using time-out (17\%), redirection (7\%), or looks of disapproval or a serious tone of voice (14\%); one parent reported that time-out was recommended by the family's pediatrician. Only two parents indicated frequent use of harsher discipline strategies (e.g., yelling), and one justified this choice by indicating that yelling had been used by respondent's own parents. No parents reported using spanking as a frequent discipline strategy. 
Table 3

Intercorrelations Among Parent Reports of Their Patience With Child, Parenting Behaviors, and Children's Options at Home $(\mathrm{N}=30)$

\begin{tabular}{|c|c|c|c|c|c|c|c|c|c|c|c|c|}
\hline Variables & 1 & 2 & 3 & 4 & 5 & 6 & 7 & 8 & 9 & 10 & 11 & 12 \\
\hline 1. Patient with child & - & & & & & & & & & & & \\
\hline 2. Home-school similarities & .12 & - & & & & & & & & & & \\
\hline 3. Montessori home & .26 & $.62^{*}$ & - & & & & & & & & & \\
\hline 4. Encourage responsibility & -.24 & -.31 & -.23 & - & & & & & & & & \\
\hline 5. Food preparation at home & .09 & .05 & .31 & .02 & - & & & & & & & \\
\hline 6. Offer choices & $.45^{*}$ & .23 & .24 & $-.45^{*}$ & .05 & - & & & & & & \\
\hline 7. Encourages independence & $.36^{*}$ & -.12 & .07 & .02 & .24 & .30 & - & & & & & \\
\hline 8. Plan activities for child & .14 & .26 & .31 & -.20 & $.38^{*}$ & .10 & .19 & - & & & & \\
\hline 9. Speak to child as adult & .15 & .06 & .02 & .15 & -.01 & .21 & .32 & -.19 & - & & & \\
\hline 10. Child chooses activities & $.38^{*}$ & .02 & .09 & -.11 & $.36^{*}$ & .24 & .30 & .22 & .17 & - & & \\
\hline 11. Respect for child & $.53^{* *}$ & .19 & .08 & -.21 & .07 & $.47^{* *}$ & .08 & .01 & .03 & .27 & - & \\
\hline 12. Child chooses clothing & $.43^{*}$ & -.08 & -.17 & .01 & .04 & .26 & .16 & -.18 & .31 & .10 & -.09 & - \\
\hline
\end{tabular}




\section{Associations Between Parents’ Knowledge of Montessori Principles and Parenting}

Pearson correlations revealed that the more parents understood the school's behavioral expectations for their child, the more likely they were to say that they had similar expectations for their child at home ( $r$ $=.42, p=.02)$ and that they ran their home in a manner consistent with Montessori principles $(r=.57, p=$ .00). However, knowledge of the school's behavioral expectations was not correlated with specific behaviors thought to reflect doing Montessori at home, such as intentionally storing children's belongings where they can reach them, allowing children freedom to choose their own activities, and engaging children in food preparation (see Table 4).

No significant associations were found between parents' knowledge of the school's behavioral and academic expectations of their child and the three parenting-style variables. Online research of Montessori principles was negatively associated with authoritarian parenting $(r=-.56, p=.00)$. Endorsement of the belief that Montessori education is not different from public education was positively associated with permissive parenting $(r=.48, p=.01)$.

\section{Associations Between Discipline Strategies and Doing Montessori at Home}

Parents were asked to report if they had ever used a number of discipline strategies with their child. Parents' reports were grouped into three sets of scores to reflect harsh (e.g., yelling, spanking), passive (e.g., ignoring, distracting), and active (e.g., discussing or problem-solving, time-out) discipline. Composite scores for harsh (4 items; $M=1.53, S D=1.17$, Min. = 0, Max. $=4$ ), passive (2 items; $M=.5, S D=0.63$, Min. = 0, Max. =2) and active (6 items; $M=4.53, S D=1.01$, Min. =2, Max. =6) discipline were computed as sum scores based on whether parents had ever used those specific discipline strategies. Several significant Pearson correlations were found between discipline strategies and other parenting behaviors. Parents who reported using harsh discipline strategies more often were less likely to offer their child the freedom to choose activities at home $(r=-.51, p=.01)$. Parents who reported greater use of passive discipline strategies were less likely to speak to their child as an adult (i.e., pronounce words correctly; $r=$ $.64, p=.02)$, and more likely to use baby talk with their child $(r=.84, p=.00)$.

\section{Discussion}

Taken together, results suggested that this sample of Montessori parents made an informed decision to select a Montessori education for their child. Even so, there was variability in parenting beliefs and behaviors within this sample; in some cases parenting was inconsistent with Montessori principles. For example, although most families recognized the value of having children's materials accessible to them (i.e., at their eye level and on open shelving), a small subset of parents reported using baby talk and harsh discipline (e.g., spanking, yelling) with their child. Havis (2009) suggested that parents may engage in parenting practices that undermine their child's Montessori education because of their own unresolved childhood issues. Parents may have unknowingly responded to their child's behavior in a harsh manner because of how their parents responded to them when they were children, for example. Havis further suggested that parents need to resolve lingering childhood issues to engage with their child in a more positive manner. Dr. Montessori echoed,

Until the adults consciously face their errors and correct them they will find themselves in a forest of insoluble problems. And children, becoming in turn adults, will be the victims of this same error, which they will transmit from generation to generation. (Montessori, 1970, as cited in Nunn, n.d.)

In the present study, greater (self-reported) patience was associated with providing children with choices, encouraging autonomy, and other behaviors that reflected doing Montessori at home. It is possible that parents who had more peaceful or positive childhoods were better able to remain emotionally calm to encourage children's independence. It is also possible, as Woo (2014) pointed out, that children's behavior 
Table 4

Correlations Between Parents' Understanding of Their School's Behavioral Expectations and Parenting Behaviors ( $=30)$

\begin{tabular}{|c|c|c|c|c|c|c|c|c|c|c|}
\hline Variables & 1 & 2 & 3 & 4 & 5 & 6 & 7 & 8 & 9 & 10 \\
\hline $\begin{array}{l}\text { 1. Understands school's } \\
\text { behavioral expectations }\end{array}$ & - & & & & & & & & & \\
\hline 2. Home-school similarities & $.42^{*}$ & - & & & & & & & & \\
\hline $\begin{array}{l}\text { 3. Home life consistent with } \\
\text { Montessori principles }\end{array}$ & $.57^{* *}$ & $.62^{*}$ & - & & & & & & & \\
\hline 4. Encourages responsibility & .05 & -.31 & -.23 & - & & & & & & \\
\hline 5. Food preparation at home & .11 & .05 & .31 & .02 & - & & & & & \\
\hline 6. Child chooses activities & .04 & .02 & .09 & -.11 & $.36^{*}$ & - & & & & \\
\hline 7. Encourages independence & .11 & .23 & .05 & .05 & .24 & .24 & - & & & \\
\hline 8. Plans activities for child & -.10 & .26 & .31 & -.20 & $.38^{*}$ & .22 & .10 & - & & \\
\hline 9. Uses baby talk with child & $-.56^{* *}$ & -.24 & -.31 & .15 & -.14 & .08 & .00 & .13 & - & \\
\hline 10. Speaks to child as adult & .21 & .06 & .02 & .01 & -.01 & .18 & .21 & -.19 & $-.55^{* *}$ & 一 \\
\hline
\end{tabular}

${ }^{*} p<.05 .{ }^{* *} p<.01$ 
problems can stem from issues within the home environment. If children are frustrated because their home environment is overly restrictive or chaotic, for example, parents may notice more tantrums at home, which can tax parents' ability to be patient.

To address home-school inconsistencies, Havis (2009) proposed that "schools must, therefore, deal with these undermining attitudes by removing the uncooperative families, if necessary, until the issue is finally resolved at home" (p. 3). This type of response from schools may be impractical and disruptive to the child, family, and school. In contrast, Epstein (2015) suggested a greater need for open communication between Montessori teachers and parents as a mechanism for fostering collaborative partnerships and "understanding family priorities" (p. 11). This approach requires teachers to be diligent about providing opportunities for families to share their perspectives about their child's education and development. In addition to parents having regular conversations with teachers, results from the present study suggest that parents may benefit from opportunities to learn about the guiding logic of Montessori principles, to explore their own parenting beliefs and practices, and to learn ways of doing Montessori in the home that do not require abandonment of their current parenting practices and routines. Specifically, parent-education programs geared toward Montessori parents could encourage positive parent-child interactions at home; developmentally appropriate language; and active, but not punitive, discipline strategies. Montessoriinspired parent-education programs also could provide parents with information about how to structure the physical environment at home to be more consistent with children's experience in their Montessori classrooms. Teachers should anticipate that parents may find it easier to alter the physical environment at home (e.g., by placing limited items on open shelving) than to alter their deeply rooted beliefs about child development and discipline. The challenge of working with parents whose beliefs about child development may not align with a Montessori perspective further underscores the importance of parent-teacher communication that honors the perspectives of both parties, while also prioritizing the needs of the child.

Parenting is deeply embedded in one's culture. For example, ethnicity and culture shape parents' values concerning their child's traits and behaviors, and variations in parents' values predict different outcomes in children's academic achievement (Okagaki \& Sternberg, 1993). Prior to drawing premature conclusions about apparent mismatches between home and school contexts, Montessori educators would benefit from understanding how families' cultural beliefs inform their parenting choices (Epstein, 2015). A potentially beneficial, albeit time-intensive, strategy is to conduct home visits with families to better understand parents' perspectives and build home-school connections (Patton, 2015). Community organizations can be valuable resources in assisting schools to develop parent-education workshops that are culturally sensitive, while gently encouraging parents to reinforce the central goals of a Montessori education at home.

The subjects in this study tended to be authoritative in their parenting style, scored relatively highly on responsiveness and reasoning, and overrepresented the higher end of the socioeconomic distribution. The site for data collection was a private Montessori school, which tends to draw families who can afford private-school tuition. Future studies that include a larger and more diverse sample of parents would be in a better position to examine how parents' gender, socioeconomic status, and culture influence their parenting beliefs and practices at home. Larger and more diverse samples from both private and public Montessori schools would also allow more rigorous statistical analyses of associations between parent and child factors associated with Montessori (or non-Montessori) practices at home (Debs, 2016).

The questions used in this study to measure doing Montessori at home asked parents to indicate if their home environment and parenting were consistent with Montessori principles. However, the fixedresponse questions provided limited information, and parents' self-reports may be biased. For example, some parents may have misperceived that their expectations of their child were similar to those of the child's school, particularly if their understanding of Montessori principles was limited. In-depth interviews with parents may uncover unrevealed influences and processes at home that facilitate or inhibit Montessori parenting. Future studies would benefit from using a mixed-method research design to better understand Montessori parents’ perspectives. 
Given the noted limitations of the present sample and research design, results from this study should be considered preliminary and thus should be interpreted with caution. Nonetheless, these results are intriguing and provide a first glimpse into the home lives of Montessori-educated toddlers and preschoolers. As researchers continue to explore this topic of inquiry, they should establish reliable, validated, and theoretically grounded survey instruments to measure parents' understanding of Montessori principles and doing Montessori in the home.

\section{AUTHOR INFORMATION}

Jill K. Walls, $\mathrm{PhD}$, is an assistant professor at Ball State University in the Family, Consumer, and Technology Education department. She can be reached at jkwalls2@bsu.edu.

\section{References}

American Montessori Society. (n.d.). Montessori at home. Retrieved from http://amshq.org/FamilyResources/Montessori-at-Home

Ansari, A., \& Winsler, A. (2014). Montessori public school pre-K programs and the school readiness of low-income Black and Latino children. Journal of Educational Psychology, 106, 1066-1079. http://dx.doi.org/10.1037/a0036799

Baumrind, D. (1967). Child care practices anteceding three patterns of preschool behavior. Genetic Psychology Monographs, 75(1), 43-88. Retrieved from http://homepages.utoledo.edu/mcaruso/honors-lifespan/baumrind.PDF

Baumrind, D. (1991). The influence of parenting styles on adolescent competence and substance use. The Journal of Early Adolescence, 11, 56-95. https://doi.org/10.1177/0272431691111004

Bronfenbrenner, U., \& Morris, P. A. (1998). The ecology of developmental processes. In W. Damon \& R. M. Lerner (Eds.), Handbook of child psychology: Theoretical models of human development, Vol. 1 (pp. 993-1028). Hoboken, NJ: Wiley.

Bronfenbrenner, U., \& Ceci, S. J. (1994). Nature-nurture reconceptualized in developmental perspective: A bioecological model. Psychological Review, 101, 568-586. http://dx.doi.org/10.1037/0033295X.101.4.568

Darling, N., \& Steinberg, L. (1993). Parenting style as context: An integrative model. Psychological Bulletin, 113, 487-496. http://dx.doi.org/10.1037/0033-2909.113.3.487

Debs, M. C. (2016). Racial and economic diversity in U.S. public Montessori schools. Journal of Montessori Research, 2(2), 15-34. https://doi.org/10.17161/jomr.v2i2.5848

El Nokali, N. E., Bachman, H. J., \& Votruba-Drzal, E. (2010). Parent involvement and children's academic development in elementary school. Child Development, 81, 988-1005. doi:10.1111/j.14678624.2010.01447.x

Epstein, A. (2015). Montessori early childhood teacher perceptions of family priorities and stressors. Journal of Montessori Research, 1(1), 1-13. https://doi.org/10.17161/jomr.v1i1.4939

Epstein, J. L. (2001). School and family partnerships: Preparing educators and improving schools. Boulder, CO: Westview Press.

Galindo, C., \& Sheldon, S. B. (2012). School and home connection and children's kindergarten achievement gains: The mediating role of family involvement. Early Childhood Research Quarterly, 27, 90103. https://doi.org/10.1016/j.ecresq.2011.05.004

Havis, L. (2009). Home-school relations. The Montessori Observer, 30(1), 2-4. Retrieved from https://ia800201.us.archive.org/26/items/ERIC_ED520736/ERIC_ED520736.pdf

Knoche, L. L., \& Witte, A. L. (2016). Strengths-based educational interventions in rural settings: Promoting child development through home-school partnerships. In L. J. Crockett \& C. Gustavo (Eds.), Rural ethnic minority youth and families in the United States (pp. 227-246). Available from https://link.springer.com/book/10.1007\%2F978-3-319-20976-0 
Lillard, A. S. (2012). Preschool children's development in a classic Montessori, supplemented Montessori, and conventional programs. Journal of School Psychology, 50, 379-401. doi:10.1016/j.jsp.2012.01.001

Lillard, A. S., \& Else-Quest, N. (2006). The early years: Evaluating Montessori education. Science, 313, 1893-1894. doi:10.1126/science.1132362

Lillard, A. S., Heise, M. J., Richey, E. M., Tong, X., Hart, A., \& Bray, P. M. (2017). Montessori preschool elevates and equalizes child outcomes: A longitudinal study. Frontiers in Psychology, 8, 1783. https://doi.org/10.3389/fpsyg.2017.01783

McCarthey, S. J. (2000). Home-school connections: A review of the literature. The Journal of Educational Research, 93, 145-153. http://dx.doi.org/10.1080/00220670009598703

McFarland, S., \& McFarland, J. (2013). Montessori parenting: An idea whose time has come. Montessori Life, 25(1), 30-39.

Montessori, M. (1970). The child in the family. New York, NY: Avon Books.

Montessori, M. (1995). The absorbent mind. New York, NY: Holt.

Murray, A. (2012). Public knowledge of Montessori education. Montessori Life, 24(1), 18-21. Retrieved from

https://t.amshq.org/Publications-and-Research/MontessoriLife/ /media/0834C9E4F0A04D928FEA5E81F28D04F9.ashx

Nunn, P. (n.d.). The prepared adult as the key to the Montessori approach for indigenous communities of Australia. Montessori Australia Foundation. Retrieved from https://montessoridigital.org/file/1995/download?token=tcpyIsuH

Okagaki, L., \& Sternberg, R. J. (1993). Parental beliefs and children's school performance. Child Development, 64, 36-56. http://www.jstor.org/stable/1131436

Patton, M. (2015). The home visit: Creating connections and building relationships with parents. Montessori Life, 27(1), 42-44. Retrieved from https://amshq.org/Publications-andResearch/Montessori-Life/ /media/A0B9070BDC22479F84C3BF6C31A70D92.ashx

Phelan, P., Davidson, A. L., \& Cao, H. T. (1991). Students’ multiple worlds: Negotiating the boundaries of family, peer, and school cultures. Anthropology \& Education Quarterly, 22, 223-249. doi:10.1525/aeq.1991.22.3.05x1051k

Pottish-Lewis, P. (2011). Elementary classroom management: How to implement cosmic education [Booklet]. American Montessori International/USA. Retrieved from https://assets1.casaschool.nl/uploads/document/file/70/Elementary_Classroom Management Cos mic Education.pdf

Qualtrics [Computer software]. (2018). Retrieved from https://www.qualtrics.com

Robinson, C., Mandleco, B., Olsen, S. F., \& Hart, C. H. (1995). Authoritative, authoritarian, and permissive parenting practices: Development of a new measure. Psychological Reports, 77, 819-830. https://doi.org/10.2466/pr0.1995.77.3.819

Schofield, T. J., \& Weaver, J. M. (2016). Democratic parenting beliefs and observed parental sensitivity: Reciprocal influences between coparents. Journal of Family Psychology, 30, 509-515. http://dx.doi.org/10.1037/fam0000166

Steinberg, L., Lamborn, S. D., Dornbusch, S. M., \& Darling, N. (1992). Impact of parenting practices on adolescent achievement: Authoritative parenting, school involvement, and encouragement to succeed. Child Development, 63, 1266-1281. http://www.jstor.org/stable/1131532

Woo, S. (2014). Creating an amazing Montessori toddler home environment. Montessori Life, 26(2), 5459. 